\title{
DIREITO A CONVIVÊNCIA FAMILIAR DAS CRIANÇAS E ADOLESCENTES EM SITUAÇÃO DE ACOLHIMENTO INSTITUCIONAL: UMA ANÁLISE PRÁTICA NO MUNICÍPIO DE TRAMANDAÍ/RS
}

\author{
THE RIGHT TO FAMILY COEXISTENCE OF CHILDREN AND \\ ADOLESCENTS IN INSTITUTIONAL CARE: A PRACTICAL ANALYSIS IN \\ THE MUNICIPALITY OF TRAMANDAÍ/RS
}

\author{
Andrei Ferreira Fredes ${ }^{*}$ \\ Daniella Luana de Brito Caran ${ }^{* *}$
}

\section{RESUMO}

O presente artigo objetivou discorrer sobre o direito constitucional a convivência familiar das crianças e dos adolescentes quando em situação de acolhimento institucional, com análise prática da situação das crianças e dos adolescentes acolhidos no munícipio de Tramandaí/RS. A pesquisa utilizou metodologia dedutiva e qualitativa, através de pesquisa documental, doutrinária e análise legislativa sobre o tema em voga, com aplicação de questionário semiestruturado e coleta de dados estatísticos sobre os acolhidos. O trabalho buscou conceituar e definir a importância do direito fundamental a convivência familiar para as crianças e adolescentes, verificando como ele vinha sendo garantido a estes indivíduos quando sob a égide do acolhimento institucional. Para melhor ilustração do tema foi apresentado os resultados da pesquisa de campo realizada no Município de Tramandaí/RS, concluindo por fim sobre os mecanismos que perpetuam a violação do referido direito.

Palavras-chaves: Direito fundamental a convivência familiar. Acolhimento institucional. Crianças e adolescentes.

\begin{abstract}
The present article aims to discuss about the constitutional right to family living of children and adolescents when under institutional care, with practical analysis of the children and adolescents' situation under institutional care in Tramandai/ RS. Deductive and qualitative methodology will be used, through documentary research, doctrinal and legislative analysis on the current issue, with application of semi-structured questionnaire and collect of statistical data about the children taken. It is primarily searched to conceptualize and define the importance of the fundamental right to family living for children and adolescents, for then verify how it has been guaranteed to these individuals when under the aegis of institutional care. Moreover, for a better illustration of the theme, it is searched to present the outcomes of the field research carried out in Tramandai/RS, to finally conclude about the mechanisms that perpetuate the infringement of that right.
\end{abstract}

Keywords: Fundamental right to family interaction. Institutional sheltering. Children and adolescents.

\footnotetext{
Doutorando e Mestre em Direito pela Pontifícia Universidade Católica do Rio Grande do Sul (PUC-RS)

"Graduada em Direito pelo Centro Universitário Cenecista de Osório (CNEC-RS)
} 


\section{INTRODUÇÃO}

O presente artigo abordará o tema do direito fundamental a convivência familiar sob a ótica do acolhimento institucional, com análise prática da situação das crianças e adolescentes acolhidas no município de Tramandaí/RS, no abrigo Casa da Criança. A temática proposta mostra-se relevante em face do dever solidário emanado da norma constitucional, entre o Estado, a família e a sociedade, em resguardar à criança e ao adolescente, com absoluta prioridade, todos os direitos e garantias a eles inerentes, colocando-os a salvo de toda e qualquer negligência, de forma a garantir o seu desenvolvimento sadio.

A preocupação com a infância e com a adolescência consubstanciada pela doutrina da proteção integral, fundamenta-se no reconhecimento da condição especial de pessoas em desenvolvimento das quais são detentores os indivíduos neste período da vida. Encontra respaldo legal no ordenamento jurídico brasileiro, através das garantias asseguradas pela Constituição Federal (CF/1988) e pelo Estatuto da Criança e do Adolescente (ECA/1990), os quais resguardam às crianças e aos adolescentes, todos os direitos fundamentais inerentes a pessoa humana e ainda outros necessários ao seu pleno desenvolvimento. Dentre estes destaca-se o direito a convivência familiar, em razão da relevância da família, como primeiro agente socializador do ser humano, através do qual o indivíduo logra concretizar uma existência digna.

A inquietude que a presente temática provoca entre os operadores do direito decorre do fato de que quando do acolhimento, a criança ou o adolescente se encontra em situação de extrema vulnerabilidade social, sendo, portanto, fundamental que o Estado haja de forma diligente na prestação da tutela protetiva, afim de não incidir na vitimização do menor.

Pelas razões acima expostas, busca-se apresentar respostas para os seguintes questionamentos: como se dá a efetivação do direito fundamental a convivência familiar da criança e do adolescente em situação de acolhimento institucional e como este direito vem sendo garantido às crianças acolhidas no município de Tramandaí/RS

Desta forma, intenta-se verificar a atuação do Estado como garantidor dos direitos fundamentais e constitucionais das crianças e adolescentes quando colocadas sob acolhimento, em especial ao direito a convivência familiar, analisando assim os mecanismos utilizados para garantir a tutela, bem como sua eficácia no plano fático em concretizar a proteção integral a eles destinada, através da análise prática no município de Tramandaí/RS.

Objetivando-se alcançar o resultado pretendido, bem como estabelecer melhor compreensão da matéria proposta, o presente artigo divide-se em dois momentos. Inicialmente, pretende-se realizar estudo documental, por meio de análise da legislação vigente, da doutrina e de artigos científicos sobre o tema em voga, com caráter descritivo e exploratório. Em seguida, realizar-se-á, na forma qualitativa uma pesquisa de campo, por meio da aplicação de questionário semiestruturado aos responsáveis pelo local, realizando um levantamento de dados estatísticos acerca do trabalho realizado pela casa de acolhimento.

Para tanto estrutura-se o trabalho em cinco títulos. Inicialmente busca-se apresentar breve abordagem sobre o histórico evolutivo da tutela de proteção ao menor, perpassando desde o período em que eram vistos apenas como objetos de direito até o seu reconhecimento enquanto sujeitos de direito, destinatários de integral proteção. Superada a contextualização histórica do tema, pretende-se apresentar a temática da proteção constitucional da criança e do adolescente, para depois adentrar no título sobre a dignidade humana e discorrer sobre o direito fundamental a convivência familiar, sua fundamentação e correlação com a dignidade humana das crianças e dos adolescentes. Em seguida busca-se analisar o acolhimento institucional e as possibilidades de garantia e de efetivação do direito a convivência familiar para a criança ou adolescente institucionalizada, com destaque especial para a situação de acolhimento institucional no Município de Tramandaí/RS. A fim de verificar a prestação da tutela protetiva para com as crianças e adolescentes acolhidas, em especial quanto a garantia do direito a convivência familiar, verificando a existência de entraves para a sua efetivação, de forma a compreender quais mecanismos corroboram para a morosidade do processo. Por derradeiro, apresentar-se-á as considerações finais sobre o trabalho realizado, discutindo-se de maneira conclusiva sobre os pontos trabalhados, reafirmando-se nesta ocasião, sua relevância social e jurídica. 


\section{HISTÓRICO DA PROTEÇÃO A CRIANÇA E AO ADOLESCENTE}

Para melhor compreensão do tema proposto faz-se necessário delinear, ainda que de forma incipiente, a evolução legislativa da proteção à criança e ao adolescente no Brasil e no mundo, desde a época em que não tinham direitos resguardados, até o seu reconhecimento enquanto sujeitos de direitos, detentores de especial proteção.

Por um longo período da história os direitos das crianças e dos adolescentes foram quase inexistentes no plano jurídico. Com o decorrer dos tempos a sociedade passou a atentar aos índices alarmantes de mortalidade, de violência, de abandono e de exploração de menores, ganhando esta preocupação espaço crescente em escala mundial. (OLIVEIRA, 2013). Iniciando assim, durante o século XIX, o processo de reconhecimento da criança como sujeito de direito com necessidades de afeto e de educação. (OLIVEIRA, 2013)

No século XX surgem em nível mundial, diversos movimentos em prol do reconhecimento dos direitos infanto-adolescentes, com a criação de relevantes dispositivos deles afirmativos, dentre eles: a Declaração de Genebra de 1924; a criação, em 1946, do Fundo Internacional de Emergência das Nações Unidas para a Infância (UNICEF); a Declaração Universal dos Direitos da Criança criada em 1959; e, a Convenção dos Direitos da Criança, criada em 1989, representando um marco histórico para os direitos infanto-juvenis, por ser o primeiro documento a orientar no sentido de uma proteção integral. Além destes, outros dispositivos internacionais influenciaram na causa, como a Declaração Universal dos Direitos Humanos de 1948 e a Conferência Especializada Interamericana sobre Direitos Humanos, criada em 1960 em San José de Costa Rica, ambos abrangendo direta ou indiretamente a proteção aos direitos das crianças. (ANDRADE, 2010)

Nota-se a esta altura, o advento de uma forte corrente humanística no âmbito do direito internacional, deflagrada após as atrocidades cometidas durante a II Guerra Mundial, o que levou a comunidade internacional a se preocupar com a efetividade da proteção aos direitos humanos, bem como do reconhecimento dos direitos da infância e da adolescência, em razão de sua fragilidade e hipossuficiência. (ANDRADE,
2010) Tais movimentos pressionaram os Estados a adotarem uma postura de proteção e responsabilização em prol das crianças e dos adolescentes, tendo reflexos positivos também no ordenamento jurídico brasileiro, que passou a reconhecer formalmente a condição especial de pessoas em desenvolvimento da qual são detentores, razão pela qual posteriormente o ordenamento jurídico nacional abarcou a doutrina da proteção integral. (ANDRADE, 2010)

\section{A PROTEÇÃO À CRIANÇA E AO ADOLESCENTE NO BRASIL}

Historicamente a família pertenceu ao domínio privado, isto é, ao modelo patriarcal, cabendo ao pai decidir acerca de seu futuro, não podendo o Estado interferir neste domínio, razão pela qual o reconhecimento da criança como sujeito de diretos é algo recente (LOBO, 2010).

No Brasil, a evolução da tutela do melhor interesse da criança e do adolescente pode ser dividida em duas etapas, passando pela época da doutrina da situação irregular até o reconhecimento dos direitos fundamentais com a doutrina da proteção integral, que entrou no ordenamento do país com a CF/88. Silva esclarece acerca da primeira doutrina vigente:
'Situação irregular', para a doutrina anterior e previs- ta no antigo Código de Menores (Lei 6.697/1.979), significava que o 'menor' somente teria visibilidade para o Estado quando estivesse em situação irregu- lar, sendo que, nesse caso, o Estado agiria no sentido de retirá-lo do convívio social e colocá-lo em ins- tituições despreparadas para atendimento à pessoa, intituladas FEBEM, contrariando, hoje, o princípio da dignidade humana. Logo, o aparato legal existen- te não tinha como objetivo a proteção do 'menor', mas sim a proteção da sociedade contra 'menores em situação irregular' (2016, p. 157).

Datam do Brasil Colônia as primeiras medidas assistenciais de proteção às crianças, como a implementação no ano de 1726 da chamada Roda dos Expostos, ou Roda dos Enjeitados, como também era conhecida. (FREITAS, 2001). Regulamentada em lei, a Roda dos Expostos configurou a principal forma de assistência infantil durante os séculos XVIII e XIX. (FREITAS, 2001). Tratava-se de um cilindro instalado na parede de uma casa, que girava de fora para dentro, onde a criança era depositada para ser 
abrigada, protegendo a identidade de quem a abandonava. (FREITAS, 2001)

No ano de 1830 tem-se no Brasil o advento do Código Penal do Império, abordando a questão da infância sob a ótica da imputabilidade penal. Institui a maioridade penal a partir dos sete anos de idade, assegurando aos menores de dezesseis anos a inaplicabilidade da pena de morte. (SARAIVA, 2013)

Com a proclamação da República, surge em 1890 o Código Penal dos Estados Unidos do Brasil, no qual responsabilizavam-se penalmente crianças de nove a quatorze anos, aplicando o critério da teoria do discernimento. (SARAIVA, 2013). Tal teoria consistia em submeter o menor infrator a uma avaliação psicológica, penalizando-o de acordo com o seu discernimento sobre o crime cometido, podendo receber pena de adulto ou ser declarado inimputável. (SARAIVA, 2013). A partir dos quatorze anos de idade o indivíduo já era considerado imputável penalmente. (SARAIVA, 2013)

Em 1927 tem-se o advento do primeiro Código de Menores, também conhecido como Código Mello Mattos, em referência ao nome do primeiro juiz de menores do Brasil e da América Latina, pelo qual foi adotada a doutrina da situação irregular. (VERONESE, 1997). Representando considerável avanço no assistencialismo infantil, instituiu-se o que hoje é chamado de medidas socioeducativas, com a institucionalização do menor em casas destinadas a esse fim. (VERONESE, 1997). Veronese aduz, em relação aos avanços trazidos pelo Código de Menores de 1927:

[...] conseguiu corporificar leis e decretos que, desde 1902, propunham-se a aprovar um mecanismo legal que desse especial relevo à questão do menor de idade. Alterou e substituiu concepções obsoletas como as de discernimento, culpabilidade, responsabilidade, disciplinando, ainda, que a assistência à infância deveria passar da esfera punitiva para a educacional (1997, p. 10).

Outro ponto que merece destaque é o emprego do termo "menor". Historicamente foi empregado com conotação negativa, definindo as crianças a margem da sociedade - por motivo de carência ou por infringir as leis -, como em situação irregular, passíveis da tutela corretiva estatal (OLIVEIRA, 2010).

Treze anos após a instituição do Código de Menores, durante o governo provisório de Getúlio Vargas, um novo Código Penal é projetado, declarando a inimputabilidade penal dos menores de dezoito anos de idade, sujeitos a medidas corretivas por lei especial (SARAIVA, 2013). Em 1941 é criado o Serviço de Assistência a Menores (SAM) ${ }^{1}$, com sistema de internato para atender essa parcela da população (SARAIVA, 2013). Foi posteriormente extinto após o golpe militar de 1964, momento em que surge no país a Política Nacional do Bem-Estar do Menor (PNBEM), para regular todas as ações na área da infância e juventude, dando origem como sucessora do SAM à Fundação Nacional do Bem-Estar do Menor (FUNABEM) e as Fundações Estaduais do Bem-Estar do Menor (FEBEMs) ${ }^{2}$ (SARAIVA, 2013).

O ano de 1988 foi significativo para os direitos das crianças e dos adolescentes, com a promulgação da Constituição Federal (SARAIVA, 2013). Diante do reconhecimento estatal de que a infância e a adolescência são períodos especiais do desenvolvimento humano, o legislador constituinte incluiu no texto da carta magna os fundamentos básicos da proteção integral. Foi compilado através do artigo $227^{3}$, os direitos fundamentais inerentes as crianças e aos adolescentes, além de reservar a Família, através do artigo 226, especial proteção, em razão de sua imensurável relevância social.

Posteriormente, sua estrutura foi complementada por lei infraconstitucional, qual seja, o Estatuto da Criança e do Adolescente (ECA), promulgado no Brasil em 13 de julho de 1990. O ECA fundamentouse na Declaração Universal dos Direitos da Criança e na Convenção Internacional sobre os direitos das crianças, abarcando a doutrina da proteção integral. Adotou o conceito de infância por critério de idade, considerando para efeitos legais, criança os indivíduos de zero a doze anos incompletos, e adolescentes de doze a dezoito anos de idade, e reconhecendo-os como pessoas em desenvolvimento (ECA, 1990).

A Constituição Federal, com a posterior promulgação do ECA, representou um divisor de águas para o direito infanto-adolescente no Brasil. Após o

\footnotetext{
${ }^{1}$ O SAM/1941 foi o primeiro órgão federal de controle da assistência a crianças, atendendo os menores abandonados e os "menores delinquentes".

${ }^{2}$ FUNABEM e FEBEM. Tais instituições foram duramente criticadas, acusadas de violência interna e ineficazes na ressocialização.

${ }^{3}$ CF. Art. 227 - É dever da família, da sociedade e do Estado assegurar à criança, ao adolescente e ao jovem, com absoluta prioridade, o direito à vida, à saúde, à alimentação, à educação, ao lazer, à profissionalização, à cultura, à dignidade, ao respeito, à liberdade e à convivência familiar e comunitária, além de coloca-los a salvo de toda forma de negligência, discriminação, exploração, violência, crueldade e opressão.
} 
seu advento, ocorreram diversas atualizações relevantes da norma legal vigente, de forma a acompanhar o desenvolvimento da sociedade. A exemplo destaca-se a Nova Lei de Adoção no 12.010 de 2009, que institui relevantes mudanças ao ECA, e o advento da Lei $\mathrm{n}^{\mathrm{o}} 13.010$ de 2014, conhecida como Lei do Menino Bernardo, a qual proíbe expressamente castigos físicos, tratamentos cruéis ou degradantes na educação das crianças e dos adolescentes ${ }^{4}$. Há que se falar ainda nas atualizações legislativas mais recentes, quais sejam as Leis 13.257 de 2016, denominada como Marco Legal da Primeira Infância e a Lei 13.509 de 2017. Esta última visa dar celeridade aos processos de adoção, bem como melhor tutelar o direito a convivência familiar. Reduziu o prazo máximo permitido para o acolhimento institucional, de dois anos para dezoito meses, e o tempo máximo estipulado para reavaliação de caso pela autoridade judiciária competente, de seis meses para três meses, de forma a melhor se adaptar ao caráter transitório da medida protetiva. ${ }^{5}$

\section{PROTEÇÃO CONSTITUCIONAL DA CRIANÇA E DO ADOLESCENTE}

A Constituição Federal de 1988 reconheceu a necessidade de se destinar a infância e a juventude, especial proteção, elevando as crianças e os adolescentes como sujeitos de direitos. Foi incorporado no bojo de seu texto a doutrina da proteção integral, já reconhecida em âmbito internacional, como dever de tutela solidário por parte do Estado, da sociedade e da família. Acerca do conceito de proteção integral, Garrido de Paula (2002, p.25) exemplifica que: "Proteção no sentido de resguardo as condições para a felicidade atual e futura. Integral porquanto devida à totalidade do ser humano, nos seus mais variados aspectos, notadamente físico, mental, moral, espiritual e social".

\footnotetext{
${ }^{4}$ Altera a Lei no 8.069 de 13 de julho de 1990 (ECA), para estabelecer o direito das crianças e dos adolescentes de serem educados e cuidados sem o uso de castigos físicos ou de tratamento cruel ou degradante.

${ }^{5}$ A Lei $n^{\circ} 13.509 / 2017$ teve partes de seu texto vetadas, a exemplo da alteração proposta ao $\$ 1^{\circ}$ do artigo 19 do ECA, que reduzia o prazo máximo para reavaliação da situação da criança ou do adolescente acolhido de 06 (seis) meses para 03 (três) meses. Em que pese o artigo $66 \$ 1^{\circ}$ da Constituição Federal conferir ao Presidente da República legitimidade para vetar, total ou parcialmente, projeto de lei inconstitucional ou contrário ao interesse público, tal hipótese não se verificou no caso concreto, tendo em vista que as razões do veto se limitaram evitar a sobrecarga do trabalho das equipes interprofissionais dos serviços de acolhimento do SUAS em detrimento do melhor interesse das crianças e adolescentes.
}

Como se verifica, a doutrina da proteção integral inserida no ordenamento jurídico brasileiro veio para resguardar a infância e a adolescência em todos aspectos de desenvolvimento psicossocial dos indivíduos.

O artigo 227 da CF/1988 trouxe uma série de direitos a serem garantidos de forma prioritária, relevantes não só pelo cunho protetivo, como também pela titularidade ao qual se destinam. Foi positivado pela norma o direito à vida, à saúde, à educação, ao lazer, a profissionalização, à cultura, a dignidade, ao respeito, a liberdade e a convivência familiar e comunitária, perfazendo esse conjunto de direitos fatores intrínsecos a efetivação da dignidade da criança e do adolescente. Bem como, mecanismos de garantia para que estes possam se desenvolver de maneira sadia. Importante salientar que a criança e o adolescente gozam de todos os direitos específicos aqui explicitados, sem prejuízo aos demais direitos e garantias fundamentais inerentes a pessoa humana.

No que tange o art. 227 da Constituição Federal, Emerique (2008, p. 112) afirma que: "O citado dispositivo menciona um conjunto de direitos fundamentais, civis e sociais que, sob a orientação da indivisibilidade e da interdependência, assegurarão a dignidade das crianças e dos adolescentes".

As mudanças advindas com a Constituição Federal de 1988 significaram consistente alteração de paradigma no modo como os interesses infanto-adolescentes eram tutelados até então, tento a nova normativa força coercitiva especialmente em face do Estado e da Família, frente ao dever/obrigação de proteção aos direitos das crianças e dos adolescentes. Destarte, na medida em que se tem constitucionalmente consolidados os direitos e garantias a eles inerentes, cabe ao Estado atuar de forma assertiva e contínua na tutela de seu melhor interesse, por intermédio de políticas públicas adequadas e eficientes, visando efetuar a promoção e defesa de seus direitos, tanto de forma preventiva como interventiva.

Dentre os direitos e as garantias acima referidos, destaca-se o direito a convivência familiar, objeto central dessa pesquisa, como premissa para a concretização dos demais direitos infanto-adolescentes. 


\section{DIGNIDADE HUMANA E O DIREITO A CONVIVÊNCIA FAMILIAR}

Acerca da dignidade humana, Rawls afirma que "cada pessoa possui uma inviolabilidade fundada na justiça que nem o bem-estar de toda a sociedade pode desconsiderar" (2016, p. 4). Em outras palavras podese dizer que o princípio da dignidade humana é um direito inalienável, indisponível e inviolável, que garante a todos os seres humanos as condições mínimas para uma vida saudável, justa e feliz, livre de qualquer ato de cunho degradante, desumano ou cruel.

Como visto, o ideal de dignidade humana influenciou diversas constituições, de diversos países, inclusive a CF/1988. A Constituição Federal de 1988 em seu título I estabelece a composição do Estado Democrático de Direito, seus fundamentos, objetivos e princípios gerais. Da leitura do título I destaca-se a inserção, pelo legislador constituinte, do princípio da dignidade humana no rol de fundamentos do Estado Democrático de Direito (CF/1988, art. $1^{\circ}$, III).

A partir do título II, o texto constitucional determina os direitos e garantias fundamentais, os quais devem alcançar todas as pessoas de forma justa e igualitária, na medida em que se estruturam a partir das concepções de dignidade da pessoa humana. Corroborando a este entendimento Araújo e Nunes ensinam que "os direitos fundamentais podem ser conceituados como a categoria jurídica instituída com a finalidade de proteger a dignidade humana em todas as dimensões" (2005, p. 109-110).

No que se refere a extensão dos direitos fundamentais, cabe destacar o teor do art. $5^{\circ}, \S 2^{\circ}$, da $\mathrm{CF} / 1988$, que determina que "os direitos e garantias expressos nesta Constituição não excluem outros decorrentes do regime e dos princípios por ela adotados, ou tratados internacionais que a República Federativa do Brasil seja parte". Em outras palavras, pode-se dizer que os direitos e garantias fundamentais não se esgotam nas disposições apresentadas pelo título II.

Assim, considerando que a dignidade da pessoa humana se constitui por uma diversidade axiológica, este princípio foi moldado conforme a evolução da sociedade, estendendo-se às crianças e aos adolescentes a partir do reconhecimento de que estes são sujeitos do direito e merecedores de tratamento especial, conforme se extrai do artigo 227 da Carta Magna, albergando seus direitos como fundamentais (SILVA, 2016).
Nesse contexto, o ideal de dignidade humana estende-se a garantia dos direitos fundamentais das crianças e dos adolescentes. Destaca-se o direito a convivência familiar, como meio pelo qual a dignidade humana desses indivíduos se concretiza, figurando a família como primeiro agente socializador humano (LIBERATI, 2010). A família figura como instituição essencial para a realização da dignidade humana das crianças e dos adolescentes, pois é o meio pelo qual desenvolvem sua personalidade, individualidade, particularidades e logram concretizar seus direitos fundamentais. Por qual razão a supressão destas garantias configura ataque aos direitos humanos e desrespeito a sua dignidade (SILVA, 2016).

Por todo o exporto, pode-se inferir que o direito a convivência familiar das crianças e dos adolescentes se correlaciona intimamente com o princípio da dignidade humana, uma vez que é por meio da família que o indivíduo logrará alcançar os seus direitos fundamentais, representando ela o espaço de pertencimento e determinação social do indivíduo.

\section{A CONVIVÊNCIA FAMILIAR ENQUANTO DIREITO FUNDAMENTAL}

Antes de iniciar a abordagem sobre a temática do direito fundamental a convivência familiar, a que se destacar o conceito de família, bem como acerca de sua relevância para a organização da sociedade. A família representa o espaço primário fundamental na formação dos seres humanos, como ambiente de humanização e socialização na qual o indivíduo é inserido ao nascer.

A inserção do instituto da família no texto constitucional (artigo 226) demonstra expressamente o interesse do legislador constituinte em elevar o referido instituto ao patamar de estrutura basilar da sociedade, merecedora, portanto, de especial proteção do Estado. No mesmo sentido, a doutrina moderna classifica a família como um conjunto de pessoas unidas por laços de sangue ou de afeto, e a considerada uma das células fundamentais da sociedade (BASTOS, 2001). Por sua vez, a Declaração Universal dos Direitos Humanos de 1948, em seu artigo 16, item 3, determina que: "a família é o núcleo natural e fundamental da sociedade e tem direito à proteção da sociedade e do Estado" (pg. 10)

Como visto, atualmente a família tem reconhecida na afetividade o seu ânimo primordial, abrangendo 
não só os laços consanguíneos como também os afetivos, de forma que o direito a convivência familiar deve ser analisado sob esse prisma, atentando para a função da família, como grupo em comunhão de vida, unido por desejo e laços afetivos (LÔBO, 2010). É através da unidade familiar que se efetiva o desenvolvimento integral dos indivíduos, razão da importância em constar no ordenamento constitucional o direito da criança e do adolescente a convivência familiar, ou seja, a crescerem, serem educados e se desenvolverem no convívio de suas famílias. Corroborando a este entendimento, ao defender a importância do núcleo familiar para o desenvolvimento das crianças Oliveira destaca que:

\begin{abstract}
A estrutura familiar, assim, traz em seu âmago não apenas a ideia de vínculos que unem as pessoas entre si, mas, sobretudo, a da existência de uma estruturação psíquica em que cada pessoa deve ter o seu lugar e exercer uma função - de filho, de pai, de mãe, etc. - além de, como unidade, ter a função de referenciar determinada pessoa na sociedade. A relevância familiar partiria da ideia acima exposta, em especial dos papéis desempenhados por cada integrante da família e da existência de afeto e respeito entre eles, importando-se destacar que eventuais privações nessas relações familiares repercutem no desenvolvimento emocional e psíquico e na formação ético moral dos seus integrantes - notadamente no desenvolvimento e na formação de crianças e adolescentes (2010, p. 396).
\end{abstract}

O ECA reafirma o rol de direitos fundamentais das crianças e dos adolescentes, dispondo em seu Capítulo III as garantias do direito a convivência familiar e comunitária. Resguardou o direito de toda a criança e adolescente ser criada e educada no seio de sua família de origem, prevendo excepcionalmente, a possibilidade em família substituta, de forma a garantir a convivência familiar. Quando o ordenamento pátrio declara o direito a convivência familiar, tem sob perspectiva um lar saudável. Todavia, quando este ambiente passa de local de proteção e zelo para sede de conflitos e abusos, o Estado deve intervir, momento em que serão aplicadas as medidas protetivas ${ }^{1}$, de forma a garantir os direitos das crianças e dos adolescentes.

Assim, embora o ECA estabeleça a manutenção prioritária da convivência da criança em sua família de

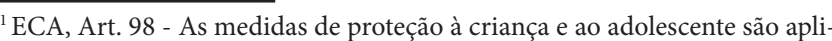
cáveis sempre que os direitos reconhecidos nesta lei forem ameaçados ou violados: I- por ação ou omissão da sociedade ou do Estado; II- por falta, omissão ou abuso dos pais ou responsável; III- em razão de sua conduta.
}

origem $^{2}$ a que se atentar para a viabilidade fática dessa manutenção, para que se reconheça quando de sua inaplicabilidade, garantindo à criança a possibilidade de ser aceita em um novo núcleo familiar, disposto a lhe propiciar afeto. Necessário se faz dar credibilidade ao poder da família substituta, como meio de se fazer garantir o direito primordial ora abordado, uma vez que a concepção atual de família é pautada no ânimo e no afeto. Lôbo esclarece a respeito da repersonalização atual da instituição familiar:

[...] vinculada por outros interesses de cunho pessoal ou humano, tipificados por um elemento aglutinador e nuclear distinto - a afetividade. Esse elemento nuclear define o suporte fático da família tutelada pela Constituição, conduzindo ao fenômeno que denominamos repersonalização (2010, pg. 28).

Não obstante o evidente reconhecimento da importância dos laços consanguíneos e parentais, necessário se mostra que a rede de proteção e os operadores do direito estejam atentos para a nova realidade das famílias, para o fim de alcançar de forma eficiente o melhor interesse das crianças e dos adolescentes. Bem como, os demais direitos fundamentais necessários à construção de sua identidade, em especial, o direito a convivência familiar, no seu sentido mais amplo e atual, qual seja, um lugar de afeto, respeito e pertencimento. Assim, quando a convivência com a família natural se torna inviável ou não aconselhável, em razão da impossibilidade do cumprimento dos preceitos constitucionais, da proteção integral e do melhor interesse do menor, cabe ao Estado o papel de salvaguardar, com absoluta prioridade, o bem-estar das crianças e dos adolescentes em situação de vulnerabilidade. Sendo este um dos principais fundamentos que legitima o Estado a aplicar a medida de acolhimento institucional.

\section{ACOLHIMENTO INSTITUCIONAL}

$\mathrm{O}$ acolhimento institucional consiste em medida protetiva prevista pelo Estatuto da Criança e do Adolescente $^{3}$, onde encontra-se as diretrizes para sua aplicação e funcionamento. De natureza provisória e

\footnotetext{
${ }^{2} \mathrm{ECA}$, Art. $19, \$ 3^{\circ}$ - A manutenção ou a reintegração de criança ou adolescente à sua família terá preferência em relação a qualquer outra providência [...] ${ }^{3}$ ECA, Art. 101. Verificada qualquer das hipóteses previstas no art. 98, a autoridade competente poderá determinar, dentre outras, as seguintes medidas: [...]VII - acolhimento institucional; (...)
} 
excepcional, visa tutelar os direitos e garantias inerentes as crianças e adolescentes quando em situação de risco social, decorrente de abandono familiar ou afastadas desse convívio quando a família age como violadora de seus direitos, seja por maus tratos, abusos ou negligência.

As casas de acolhimento, antigamente denominadas de abrigos, são instituições governamentais ou privadas (neste caso, normalmente ligadas a entidades religiosas), de aparência residencial comum. Nelas as crianças poderão ficar pelo período máximo de dezoito meses, com reavaliação trimestral de sua situação. Deverão receber atendimento individualizado e um plano individual de atendimento (PIA), desenvolvido por equipe técnica com a oitiva dos pais ou responsáveis e do acolhido, objetivando prioritariamente o retorno a família natural, em segundo plano a busca pela família extensa e em último caso, a destituição do poder familiar com a colocação em família substituta.

Tais procedimentos reclamam celeridade, a fim de minimizar os impactos psicológicos e emocionais decorrentes da situação do acolhimento bem como da supressão do direito fundamental a convivência familiar. Assim, as instituições devem trabalhar para que o período de acolhimento seja o mais breve possível, em que pese a demora efetiva, decorrente da burocracia procedimental.

O ECA estabelece os princípios norteadores a serem adotados pelas instituições no desenvolvimento de programas de acolhimento, consistindo estes em mecanismos de promoção ao direito a convivência familiar e comunitária, através da valorização dos vínculos familiares, privilegiando-se a reintegração das crianças e dos adolescentes a suas famílias de origem (natural ou extensa), bem como a inserção em família substituta, quando da sua impossibilidade, com a devida preparação desde o início do acolhimento para a ocasião do desligamento. O ECA orienta ainda, acerca da manutenção dos grupos de irmãos, assim como da forma de atendimento aos acolhidos, para que seja realizada atividades em regime de coeducação, educação conjunta para pessoas de ambos os sexos, em grupos pequenos e de forma personalizada, atentando para as individualidades de cada um. Prevê ainda, como regra, a manutenção do acolhido em uma mesma instituição, evitando, sempre que possível, que sejam realizadas transferências.
A criança ou o adolescente será encaminhado ao acolhimento através da expedição da denominada Guia de Acolhimento ${ }^{4}$. Sendo que a sua inserção no acolhimento institucional assim como sua manutenção e posterior desligamento, somente poderá ser feito por via judicial. Em casos excepcionais e de urgência, o acolhimento poderá ocorrer por meio do conselho tutelar, comunicando-se o ocorrido a autoridade judiciária competente no prazo de vinte e quatro horas.

Dentre as medidas de proteção previstas no ECA, a do acolhimento institucional caracteriza-se por sua delicada execução, em razão da relevância do direito a Convivência Familiar para as crianças e adolescentes, devendo ser aplicada em última instância, priorizando-se as medidas mais brandas, que visem o fortalecimento das unidades familiares. As medidas protetivas podem ser aplicadas ainda de forma cumulativa, levando-se em conta na sua aplicação as necessidades pedagógicas, preferencialmente as que estimulem o fortalecimento dos vínculos familiares e comunitários, sempre em prol da proteção integral e do melhor interesse da criança. Ocorre, que não é o que se observa no dia a dia das muitas casas de acolhimento espelhadas pelo país, sendo muito criticada a indiscriminada utilização da medida do acolhimento antes do exaurimento de outras mais amenas, conforme orienta o ECA.

Aplica-se a medida de acolhimento muitas vezes de maneira indevida, quando o mais adequado seria trabalhar com a família junto a Rede de Proteção, na busca do melhor resultado possível, qual seja, a reestruturação das unidades familiares. A esse respeito Veronese (2017), realiza uma crítica a tradição que se tem no país em utilizar a institucionalização de crianças e adolescentes como medida de proteção em resposta aos desvios decorrentes das condições socioeconômicas das famílias em situação de pobreza e exclusão social, como mecanismo de correção, quando a real necessidade seria de políticas públicas de fomento e promoção da família.

Acerca deste tópico, conclui-se que o rompimento dos vínculos familiares é extremamente gravoso para o menor e para sua família, cabendo ao Estado fomentar a manutenção das unidades familiares em detrimento a sua dissolução. Para tanto, a medida do

\footnotetext{
${ }^{4}$ Cartilha onde constará as informações relevantes para sua identificação, de seus pais ou responsáveis, família extensa ou terceiros interessados em sua guarda, seu endereço familiar e os motivos que provocaram seu acolhimento.
} 
acolhimento deve ser empregada apenas em situações de maior gravidade - risco a integridade física e ou/ psicológica da criança ou do adolescente -, a fim de que não acabe banalizada, e, quando da sua real necessidade, que respeite o caráter provisório da medida, de forma a assegurar o direito a convivência familiar, seja em família natural, extensa ou substituta.

\section{FAMÍLIA NATURAL, EXTENSA E SUBSTITUTA}

Após abordar o instituto do acolhimento institucional, há que se tratar acerca das medidas a serem adotadas tão logo a criança ou o adolescente adentre o sistema do acolhimento, de forma a garantir a sua devida finalidade, qual seja, uma medida protetiva excepcional e transitória. Dando-se preferência em uma escala valorativa, àquelas que visem a manutenção dos vínculos familiares e comunitários.

Dessa forma, as equipes das casas de acolhimento deverão realizar um trabalho inicial visando primordialmente o rápido retorno da criança/adolescente a família natural, com vista a manutenção dos vínculos familiares. Assim, tão logo verifique-se possível a reintegração do acolhido em sua família de origem, aciona-se a rede de proteção para que sejam inseridos em programas de apoio e promoção da família, atuando na recuperação do núcleo familiar. Acerca da importância da manutenção das famílias, Souza aduz:

Os sentidos de apego e pertencimento familiar devem ser prestigiados pelos órgãos públicos e privados da rede de proteção, posto que, o rompimento inadequado dos vínculos familiares e/ou parentais provoca sérias consequências psicológicas [...] (2014, p.176)

Quando da sua impossibilidade, busca-se a família extensa, também denominada de família ampliada, compreendida por parentes consanguíneos, ligados ao acolhido por vínculos de convivência e afeto, quais sejam, avós, tios, irmãos e etc., a fim de minimizar o abalo psicológico que o afastamento familiar possa vir a causar (FACHINETTO, 2009).

Em casos mais graves, onde a conduta dos genitores ou responsáveis torne inconcebível a manutenção do poder familiar, ou, quando frustrados todos os esforços no sentido da manutenção dos vínculos familiares, inicia-se a preparação das crianças e adolescentes para o encaminhamento a família substituta, devendo ser realizado de modo breve, tão logo se verifique a impossibilidade de retorno a família natural ou extensa. Nas palavras de Fachinetto:

Para o Estatuto da Criança e do Adolescente, criança e adolescente têm o direito de ser criados e educados pelos pais biológicos, sob pena de violação do direito a convivência familiar e, apenas quando esses violarem gravemente os deveres inerentes ao poder familiar é que se deve permitir sua retirada da família natural. (2009, p.69)

Quanto ao encaminhamento para família substituta, o ECA ${ }^{5}$ define meios para que seja realizada sua preparação e posterior acompanhamento, atentando sempre para os sentimentos do acolhido, que deverá ter sua opinião considerada, de acordo com o seu estágio de maturidade e nível de compreensão, reservando-se aos maiores de doze anos de idade a necessidade de consentimento para que o processo se realize. Prevê ainda o não desmembramento de grupos de irmãos, que devem ser encaminhados para a mesma família substituta, para o fim de garantir a manutenção dos vínculos familiares ${ }^{6}$.

Outro ponto que merece destaque é a previsão constante no ordenamento de colocação em família substituta estrangeira - por meio de adoção -, em casos de grande excepcionalidade, em razão do evidente impacto que tamanha mudança pode acarretar ao psicológico do indivíduo acolhido. Há que se falar ainda no acolhimento de crianças ou de adolescentes provenientes de comunidades indígenas ou quilombolas, aos quais o ECA destina procedimento especial, de forma a respeitar os seus costumes, crenças e tradições, buscando privilegiar sua própria comunidade ou etnia quando da necessidade de recolocação familiar.

No tocante as medidas existentes no sentido de promover o direito a convivência familiar e comunitária às crianças e adolescentes, destaca-se o programa Família Acolhedora, e o programa de apadrinhamento. A família Acolhedora funciona como medida alternativa a institucionalização, prevendo a possibilidade de acolhimento da criança ou do adolescente em unidades familiares estruturadas e aptas

\footnotetext{
${ }^{5}$ Encontra-se disposto no ECA a partir do artigo. 28, acerca da colocação de crianças e adolescentes em família substituta.

${ }^{6}$ A lei admite solução diversa em caráter excepcional.
} 
a propiciar proteção, zelo e afeto, de forma transitória, até o seu possível retorno a família de origem ou colocação em família substituta. Já o programa de apadrinhamento consiste em propiciar a criança ou o adolescente institucionalizado convivência familiar e comunitária em família que o receba aos finais de semana, priorizando neste aspecto aos acolhidos com menor possibilidade de retorno a família ou adoção. Ambas as medidas visam a redução de danos, com a inserção do menor em ambiente familiar estruturado e apto a lhe receber, de forma a minimizar os traumas decorrentes do acolhimento, porém muitas comarcas ainda não fazem uso dessas alternativas, por falta de recursos para sua implementação.

Por todo o exposto, pode-se inferir que cabe aos agentes estatais a responsabilidade de salvaguardar a situação das crianças e dos adolescentes mantidos sob a égide do acolhimento institucional. Objetiva-se que essa situação cumpra seu caráter temporário, garantindo a convivência familiar seja no seio da família natural, extensa ou substituta, quando couber. Para tanto, o Estado deve investir todos os esforços necessários para que a medida do acolhimento não acabe por vitimar a criança ou o adolescente, sob pena de violação da primazia do princípio da proteção integral, sendo o aspecto temporal fator primordial neste caso.

\section{ACOLHIMENTO NO MUNICÍPIO DE TRAMANDAÍ/RS}

Superada a análise teórica, busca-se enriquecer o trato da matéria com a apresentação dos resultados da pesquisa de campo realizada na casa de acolhimento do município de Tramandaí/RS. A fim de verificar no plano prático como ocorre a concretização dos ditames constitucionais em relação as crianças e aos adolescentes acolhidos, com enfoque especial nos procedimentos práticos utilizados para garantir o direito a convivência familiar. Busca-se analisar se os referidos procedimentos se mostram eficientes para assegurar o melhor interesse das crianças e dos adolescentes em situação de acolhimento institucional.

Utilizar-se-á como instrumento de pesquisa a aplicação de questionários e entrevistas semiestruturadas, realizadas com a Coordenadora da casa e com a Assistente Social.
$\mathrm{O}$ acolhimento institucional no município de Tramandaí/RS funciona na chamada Casa da Criança ${ }^{7}$, uma residência ampla, sobrado, de aparência discreta, sem qualquer tipo de identificação, localizada em zona residencial do Centro da cidade.

Em que pese o caráter excepcional da medida de acolhimento, pode-se observar que na casa de acolhimento de Tramandaí, tem-se uma estrutura e funcionamento interno semelhante à de uma residência comum, respeitando-se regras de convivência interna, bem como horários de descanso, alimentação, escola e lazer, realizando todas as atividades de convivência comunitária de acordo com a faixa etária de cada um. A referida organização visa diminuir os impactos negativos intrínsecos à medida de acolhimento.

A reação das crianças e adolescentes ao serem acolhidos, como se pode supor, é de grande revolta. Inicialmente eles não aceitam estar ali, se recusam a comer ou a tomar banho, pois, por "pior" que a família seja, sempre querem permanecer com elas. Nas palavras da Assistente Social:

Quanto mais tempo acolhida a criança ou o adolescente, maior é o seu sofrimento físico, espiritual e mental e em todos os contextos, adoecem emocionalmente. No acolhimento tudo é coletivo, sendo difícil para a equipe trabalhar com os acolhidos a autonomia de sujeito. As crianças e os adolescentes não possuem quarto próprio, ou objetos pessoais, de forma que indivíduo tem prejudicado seu senso de pertencimento, já que não possuem nada seu (sic)

Quanto aos aspectos organizacionais, a Casa opera com equipe composta pela coordenadora do local, uma assistente social, doze monitoras, três cozinheiras, uma servente e uma lavadeira. E não possuem transporte ou motorista no local, para realizar as diligências necessárias.

Segundo o relato das entrevistadas, a infraestrutura da casa atende as crianças e os adolescentes em suas necessidades, pois tudo que é material eles têm ali. Logo que chegam ao acolhimento, são encaminhados para rede de saúde pública a fim de verificar a saúde pregressa (dentista, oftalmologista, neurologista, vacinas), recebem acompanhamento psicológico e psiquiátrico quando necessário.

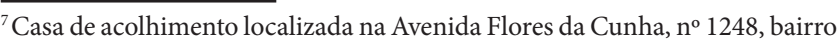
Centro, no município de Tramandaí/RS, fundada no ano de 1990, a casa tem um plano de reordenamento desde 2010. Estavam em outra casa e mudaram em 2014 para comportar o reordenamento de fato.
} 
Quanto as acomodações físicas, a estrutura conta com cinco quartos, seis banheiros, duas salas interativas, cozinha, lavanderia, garagem, uma sala da coordenação e outra da equipe técnica.

Segundo as informações prestadas pela Assistente Social, que trabalha no local a oito anos, a Casa possui capacidade para atender vinte pessoas e a quantidade de acolhidos é muito sazonal, tendo alcançado o número máximo de vinte e cinco acolhidos. Conforme se verifica na tabela abaixo, nos últimos 05 cinco anos, a casa atendeu a totalidade aproximada de cento e setenta e uma crianças e adolescentes acolhidas.

Tabela 1 - Crianças e adolescentes acolhidos nos últimos 05 (cinco) anos em Tramandaí/RS.

\begin{tabular}{l|l}
\hline Ano & Quantidade \\
\hline 2017 & 37 \\
\hline 2016 & 31 \\
\hline 2015 & 38 \\
\hline 2014 & 41 \\
\hline 2013 & 24 \\
\hline Total & 171 \\
\hline
\end{tabular}

Fonte: dados coletados em pesquisa de campo.

No momento da entrevista, a casa contava com onze acolhidos entre crianças e adolescentes de quatro a dezessete anos de idade, dentre os quais dois eram portadores de necessidades especiais.

Dentre as principais razões dos acolhimentos atuais, ganha destaque os delitos de negligência, seguida por abandono, maus tratos, abuso sexual e violência física. Não raras as vezes, as causas do acolhimento são cumulativas, isto é, os pais submetem seus filhos menores a diversas situações de perigo, violência ou negligência de forma concomitante.

Segundo os relatos colhidos, as razões que ensejam o acolhimento também são sazonais. Antigamente observava-se demanda maior por espancamento e maus tratos. Hoje, o principal motivo é a negligência, o abandono e ainda, a falta de estrutura básica, como um banheiro. ${ }^{8}$

\footnotetext{
${ }^{8}$ Embora a lei preveja expressamente que a carência material não será causa para o acolhimento, em determinados casos as crianças e/ou adolescentes acabam sendo abrigados por negligência familiar decorrentes de problemas dessa ordem.
}

Tabela 2 - Crianças e adolescentes acolhidas atualmente em Tramandaí/RS e razões que ensejaram o acolhimento

\begin{tabular}{l|l|l}
\hline Idade & Sexo & Razão do acolhimento \\
\hline $\begin{array}{l}\text { anos } \\
08 \\
\text { anos }\end{array}$ & Feminino & Negligência (especial) \\
\hline $\begin{array}{l}08 \\
\text { anos }\end{array}$ & Masculino & $\begin{array}{l}\text { Negligência } \\
\text { negligência }\end{array}$ \\
\hline $\begin{array}{l}12 \\
\text { anos }\end{array}$ & Masculino & $\begin{array}{l}\text { Abandono, negligência e violência } \\
\text { física }\end{array}$ \\
\hline $\begin{array}{l}12 \\
\text { anos }\end{array}$ & Feminino & Situação de rua / prostituição \\
\hline $\begin{array}{l}13 \\
\text { anos }\end{array}$ & Masculino & Negligência e abandono e \\
\hline $\begin{array}{l}15 \\
\text { anos }\end{array}$ & Masculino & $\begin{array}{l}\text { Maus tratos, abandono e } \\
\text { negligência (especial) }\end{array}$ \\
\hline $\begin{array}{l}16 \\
\text { anos }\end{array}$ & Masculino & Negligência e abandono \\
\hline $\begin{array}{l}16 \\
\text { anos }\end{array}$ & Masculino & $\begin{array}{l}\text { Suspeita de abuso sexual, } \\
\text { negligência e abandono }\end{array}$ \\
\hline $\begin{array}{l}16 \\
\text { anos }\end{array}$ & Feminino & $\begin{array}{l}\text { Abuso sexual, maus tratos, } \\
\text { abandono e negligência }\end{array}$ \\
\hline $\begin{array}{l}17 \\
\text { anos }\end{array}$ & Masculino & $\begin{array}{l}\text { Negligência/ pais envolvidos com } \\
\text { tráfico de drogas }\end{array}$ \\
\hline
\end{tabular}

Fonte: dados coletados em pesquisa de campo

Os pais, muitas vezes, quando da aplicação da medida do acolhimento, chegam nervosos no local, clamando pelo retorno da guarda de seus filhos. Segundo experiência da equipe da casa, na maioria das vezes desconhecem a causa do acolhimento, isto é, não sabem identificar o que é uma negligência ou maus tratos, em razão do contexto de fragilidade econômica e social em que as famílias dos indivíduos atendidos pelo acolhimento encontram-se inseridas, levando a uma reprodução de paradigmas de violações aos direitos infanto-adolescentes.

\section{MECANISMOS DE EFETIVAÇÃO E ENTRAVES ENCONTRADOS NA PROMOÇÃO DO DIREITO A CONVIVÊNCIA FAMILIAR NA CASA DA CRIANÇA, EM TRAMANDAÍ/RS}

Como visto, um dos principais obstáculos que a equipe do local apontou como motivo que mais impede o retorno dos acolhidos a família natural é a ausência de capacidade das famílias em se adaptarem 
as mudanças necessárias para receber a criança ou o adolescente de volta.

A disfuncionalidade das famílias soma-se a prática frequentemente realizada pelo Conselho Tutelar ${ }^{9}$, em encaminhar as crianças e os adolescentes diretamente para o acolhimento institucional - quando o mais adequado seria a rede de proteção: CRAS, CRES, CAPS, o que tende a dificultar a situação das crianças e dos adolescentes e a diminuir a possibilidade efetiva de reconstrução do núcleo da família natural. Corroborando a este entendimento a Assistente Social do local asseverou que:

$\mathrm{O}$ acolhimento institucional pode traumatizar a criança ou o adolescente, ainda assim, na prática, as instituições competentes estão a optar pelo caminho mais fácil, esquivando-se do problema. A lei determina que o acolhimento institucional é a última instância, porém muitas vezes tem-se demonstrado como primeira (sic)

Outro entrave explicitado pela Assistente Social, para a efetivação do direito a convivência familiar, seria quanto ao não desmembramento de grupos de irmãos. Para ela, trata-se de um problema jurídico, uma vez que grupos de irmãos possuem o processo unificado, onde um trava o andamento do outro e que, na prática, verifica-se uma enorme inviabilidade para adoção em grupos, que costumam ocorrer no máximo em casos de dois irmãos. Além disso, aduz que muitas das vezes, tratando-se de grupo de irmãos, nem sempre se demonstra a existência de vínculos afetivos e que, ainda assim, os processos permanecem unificados, retardando os procedimentos para adoção.

A individualidade de atendimento se mostra muito importante, ficando claro que no atendimento das crianças e adolescentes encaminhadas ao local, cada caso é um caso diferente, devendo ser trabalhado dentro de suas especificidades. Assim, logo após a entrada do acolhido, realiza-se as entrevistas com os familiares e conselho tutelar, a fim de verificar a situação. Constatando não ser caso para acolhimento contata-se o judiciário de imediato para providenciar o retorno da criança ou do adolescente. Ademais, a família natural sempre terá prioridade, levando-se em conta no processo a razão do acolhimento e a entrevista realizada pela assistente social. É importante constatar se os pais ou responsáveis tem real interesse

${ }^{9}$ Em Tramandaí/RS, tem-se como prática o Conselho Tutelar decidir acerca da aplicação da medida de acolhimento. em ficar com os menores, a fim de que não se invista esforços em famílias que não querem o indivíduo.

A assistente social entrevistada, que trabalha no local a muitos anos, disse nunca desistir de um acolhido e se mostrou bastante engajada na causa das crianças e adolescentes em situação de acolhimento. Segundo ela, a equipe do local realiza trabalho sensível no atendimento aos acolhidos, se empenhando ao máximo para a reintegração destes a família de origem, realizando até as diligências solicitadas junto as famílias para que possam recebê-los de volta.

Os atendidos são preparados para o desligamento desde o momento que entram no acolhimento. $\mathrm{Na}$ Casa da Criança, raras foram as ocasiões ${ }^{10} \mathrm{em}$ que uma criança ou adolescente acolhida tenha atingido o tempo máximo de permanência descrito pela lei. Segundo relato das entrevistadas, estima-se como tempo médio de acolhimento o período de seis meses.

Quanto aos adolescentes, trabalha-se a partir dos dezesseis anos de idade a preparação para o desligamento definitivo, por ocasião da maioridade civil. Assim, estes são encaminhados ao mercado de trabalho, como jovens aprendizes ou bolsista. As entrevistadas relataram ainda acerca da ansiedade sofrida pelos acolhidos ao se aproximar dos dezoito anos de idade, por não saberem o que esperar após o desacolhimento. Mas que normalmente se encaminham, encontram familiares, amigos ou até pessoas da igreja, aptas a lhes auxiliar. A instituição sempre disponibiliza após o desacolhimento uma sexta básica pelo período de seis meses, para lhes auxiliar nessa nova fase de suas vidas.

Quanto aos desfechos dos casos, analisados os últimos cinco anos, pode-se observar que na Casa da Criança em Tramandaí/RS, em 33,33\% dos casos as crianças e/ou adolescentes são restituídas as suas famílias de origem, conforme preconiza a lei. Em 20,47 $\%$ dos casos, alcançam a família extensa e em $22,22 \%$ dos casos, são recebidas em famílias substitutas através da adoção. Com uma minoria de desfechos menos satisfatórios, representados pelo total de $23,98 \%$ de casos de permanência, evasão ou alcance da maioridade. Conclui-se, assim, que no período analisado, 76,02 $\%$ dos acolhidos tiveram como desfecho a garantia do direito a convivência familiar.

\footnotetext{
${ }^{10} \mathrm{~A}$ assistente Social relatou um caso deveras tocante, de um rapaz que se encontra acolhido a oito anos, prestes a completar maioridade civil. Trata-se do maior período de duração de um acolhimento no local, em um caso bastante complexo, onde todas as instituições responsáveis - Estado, família e sociedade - visivelmente falharam na proteção e garantia aos direitos desse indivíduo.
} 
Tabela 3 - Desfechos de casos nos últimos cinco (05) anos.

\begin{tabular}{l|l|l|l|l|l|l}
\hline Ano/total de acolhidos & $\begin{array}{l}\text { Reintegração } \\
\text { familiar }\end{array}$ & $\begin{array}{l}\text { Família } \\
\text { extensa }\end{array}$ & $\begin{array}{l}\text { Família } \\
\text { substituta }\end{array}$ & Permaneceram & Evadiram & Maioridade \\
\hline $2017 / 37$ & 11 & 07 & 10 & 02 & 03 & 04 \\
\hline $2016 / 31$ & 06 & 10 & 07 & 05 & 03 & - \\
\hline $2015 / 38$ & 06 & 09 & 10 & 07 & 06 & - \\
\hline $2014 / 41$ & 22 & 05 & 07 & 04 & 03 & - \\
\hline $2013 / 24$ & 12 & 04 & 04 & 04 & - & - \\
\hline Total: 171 & 57 & 35 & 38 & 22 & 15 & 04 \\
\hline
\end{tabular}

Fonte: dados coletados em pesquisa de campo.

\section{CONSIDERAÇÕES FINAIS}

O direito a convivência familiar das crianças e dos adolescentes em situação de acolhimento institucional mostra-se como temática fortemente relevante, em decorrência do dever solidário emanado da norma constitucional, entre Estado, família e sociedade em resguardar a estes indivíduos, detentores da condição especial de pessoas em desenvolvimento, todos os direitos e garantias a eles inerentes. Notadamente quanto a importância da família neste período da vida, amplamente reconhecida como base estrutural através da qual a criança e o adolescente logram se desenvolver de maneira saudável nos mais diversos aspectos, na construção de cidadãos que serão o futuro da sociedade.

Desta forma, se mostra necessário que a rede de proteção e os operadores do direito desenvolvam um olhar mais atento para as crianças e adolescentes institucionalizados, comumente invisíveis para a sociedade, afim de que não se sintam desamparados e esquecidos, principalmente em uma necessidade tão elementar como a de fazer parte de uma família, local em que se sintam incluídos, amparados e seguros.

$\mathrm{O}$ acolhimento institucional consiste em medida protetiva que paradoxalmente a sua finalidade de preservar os direitos da criança e o adolescente demostra que está foi vítima de violação destes, o que culminou com a institucionalização. Invariavelmente, a criança e o adolescente que adentra o acolhimento, traz em sua bagagem uma história de vida de carência e violações aos mais diversos direitos, em decorrência das latentes desigualdades sociais e pobreza que assolam o país e levam muitas famílias a uma situação de exclusão social.

A partir da pesquisa realizada, foi possível concluir que as famílias atendidas pelo acolhimento institucional são, em regra, famílias de baixa renda, em situação de extrema pobreza. A situação de vulnerabilidade social em que se encontram inseridas interferem no bom funcionamento das unidades familiares, na medida em que o desemprego, a falta de acesso à educação, cultura, saúde, moradia digna e etc., muitas vezes levam os pais ao abandono de seus filhos, por não vislumbrarem meios para o exercício da responsabilidade parental. Desta forma, cabe ao Estado e a toda sociedade o desafio de garantir a estes indivíduos rápido amparo, afim de que as crianças e os adolescentes não sejam violados em um direito tão relevante como o da convivência familiar.

O tempo é fator prejudicial para o indivíduo institucionalizado. Muitas vezes, devido à morosidade dos processos, a criança nem retorna para a família de origem, nem são colocadas em família substituta, e acabam se tornando inadotáveis ${ }^{11}$, em razão dos longos períodos acolhidas. Não se pode mensurar o sentimento que o acolhimento causa as pessoas a ele submetidas, a desesperança em crescer em uma casa a que não pertence, na angustiosa espera, sem possuir nada que seja seu, principalmente o amor de uma família. Comumente perde-se a infância neste caminho, restando a criança violada no direito a convivência familiar - essencial para o seu desenvolvimento psicossocial sadio - bem como em outros diversos direitos fundamentais.

Entende-se que o acolhimento institucional sugere medida de proteção, aplicada quando a criança ou o adolescente encontra-se em situação de abandono ou vitimados em relevante direito. Desta forma, há que se atentar para a real possibilidade de reintegração

\footnotetext{
${ }^{11}$ A doutrina refere-se aos "inadotáveis" para designar as crianças e adolescentes fora do perfil comumente procurado para adoção, por fatores como idade, sexo, etnia ou em caso de portadores de necessidades especiais.
} 
familiar, que deve consistir em um lar harmonioso e seguro, e não em sede de conflitos e origem de traumas. A pesquisa demonstrou que insistir em uma reintegração familiar, quando a família muitas vezes reincidente, não se compromete em realizar as mudanças necessárias para receber o menor, pode ser mais gravoso que a destituição do poder familiar. Nesse sentido, a pesquisa realizada em Tramandaí demostrou eficiência e funcionalidade dos agentes que trabalham nesta causa, visando um procedimento célere, tanto no que tange ao retorno a família de origem ou extensa quanto o encaminhamento para a substituta. Ainda que seja importante pontuar a existência significativa de desfechos menos satisfatórios, representados, nesta pesquisa, pelo total de $23,98 \%$ de casos de permanência, evasão ou alcance da maioridade.

Cumpre ainda destacar a grande falha sistêmica, referenciada pela doutrina e corroborada pela pesquisa de campo na Casa da Criança em Tramandaí/RS, que demonstra o emprego indiscriminado da medida do acolhimento institucional como meio de órgãos responsáveis se eximirem da responsabilidade, quando o adequado seria a aplicação de medidas protetivas menos gravosas, com o encaminhamento das famílias para a rede de proteção e programas de apoio e promoção familiar. $\mathrm{O}$ acolhimento traumatiza a criança e ao adolescente, sendo incabível a sua aplicação de forma errônea, principalmente em casos de vulnerabilidades decorrentes de carência material, já que a lei veta expressamente tal medida. Assim, conclui-se que as políticas públicas e o efetivo atendimento em rede são fundamentais para a redução dos altos índices de acolhimento.

Ademais, pode-se verificar através da pesquisa de campo, a realização de trabalho primoroso no município de Tramandaí/RS, visível no interesse demonstrado pelo bem-estar dos atendidos, bem como no referido engajamento que as responsáveis pelo local relataram, em ajudar as famílias a se adaptarem para receber de volta a criança ou o adolescente. Tal atitude veste-se de cunho muito positivo e relevante, posto que as crianças e os adolescentes acolhidos já se encontram extremamente fragilizados pela situação vivenciada, sendo imprescindível este cuidado no trato para com eles, de forma que se sintam apoiados e consigam construir com a equipe da casa uma relação de confiança e carinho.
Neste sentido, entende-se acerca da importância de as instituições de acolhimento contar com uma equipe preparada para lidar com a situação de vulnerabilidade pronta para atender os acolhidos da melhor forma possível, apoiando-os e propiciando um ambiente capaz de que enquanto acolhidos consigam lidar da melhor forma possível com as adversidades provenientes de sua situação.

Conclui-se que o trabalho realizado no município de Tramandaí demonstra eficiência em buscar para as crianças e adolescentes acolhidos o direito a convivência familiar, com uma média de tempo de acolhimento satisfatória, dentro da reserva do possível pelo caráter burocrático da medida e dificuldades sociais enfrentadas. Encontrando, porém, entraves sistêmicos, como as falhas na rede de proteção e dificuldades jurídicas para tutelar situações de fato, como na dificuldade relatada em realizar o desmembramento de grupos numerosos de irmãos, em detrimento ao melhor interesse destes. Nota-se ainda, a ausência no município de programas como Família Acolhedora e de apadrinhamento dos acolhidos, existentes para minimizar os danos psicológicos que está situação atípica desenvolve nos indivíduos, e, ainda pouco implementado em muitas comarcas, o que garantiria ainda mais efetividade ao serviço, tendo em vista a possibilidade de oferecer medidas específicas capazes de alcançar àqueles jovens que poderiam evadir ou alcançar a maioridade dentro da casa de acolhimento.

Por fim, entende-se que como sociedade, ainda estamos longe do ideal de proteção integral preconizados pela norma constitucional e infraconstitucional, sendo necessária a união entre família, sociedade em geral e o Estado, no ideal de concretizar tal proteção, entendendo que a criança e o adolescente de hoje, carregam consigo o futuro da sociedade, pois serão os futuros cidadãos geradores do amanhã.

\section{REFERÊNCIAS}

ANDRADE, Lucimary B. Pedrosa. Educação infantil: discurso, legislação e práticas institucionais [online]. São Paulo: Editora UNESP; São Paulo: Cultura Acadêmica, 2010.

ARAUJO, Luiz Alberto David; NUNES JÚNIOR, Vidal Serrano. Curso de Direito Constitucional. 9. ed. São Paulo: Saraiva, 2005.

BASTOS, Celso Ribeiro. Curso de Direito Constitucional. 22. ed. São Paulo: Saraiva, 2001. 
BRASIL. Constituição (1988). Constituição da República Federativa do Brasil.

Brasília, DF: Senado Federal, 1988. Disponível em: <www. planalto.gov.br/ConstituiçãoCompilado.htm>. Acesso em: 01 de novembro de 2017.

Código Penal do Império. 1830. Disponível em:

$<$ http://www.planalto.gov.br/ccivil 03/leis/lim/LIM-16-121830.htm>. Acesso em: 01 de novembro de 2017.

Código Penal dos Estados Unidos do Brasil. 1890. Disponível em: <http://www.planalto.gov.br/ccivil_03/ decreto/1851-1899/d847.htm $>$. Acesso em: 01 de novembro de 2017 .

Código de Menores. Decreto $n^{0}$ 17.943-A. 1927. Disponível em: < http:/www.planalto.gov.br/ccivil 03/ decreto/1910-1929/d17943a.htm $>$. Acesso em: 01 de novembro de 2017.

Código de Menores. Lei n ${ }^{\circ} 6.697,1979$. Disponível em: <http://www.planalto.gov.br/ccivil_03/leis/1970-1979/ L6697.htm >. Acesso em: 01 de novembro de 2017.

Estatuto da Criança e do Adolescente (ECA) - Lei no. 8.069. Brasília, DF: Senado Federal, 1990. Disponível em: <http://www.planalto.gov.br/ccivil_03/Leis/ L8069.htm>. Acesso em: 01 de novembro de 2017.

Lei de Adoção. Lei $n^{\circ} 12.010$, de 3 de agosto de 2009. Brasília: DF. Disponível em: < http://www.planalto. gov.br/ccivil_03/_ato20072010/2009/lei/112010.htm>. Acesso em: 01 de novembro de 2017.

Lei Menino Bernardo. Lei $n^{\circ} 13.010$, de 26 de junho de 2014. Brasília: DF. Disponível em: http://www. planalto.gov.br/ccivil_03/_Ato2011-2014/2014/Lei/L13010. htm. Acesso em: 01 de novembro de 2017.

Marco da Primeira Infância. Lei $n^{\circ} 13.257$, de 08 de março de 2016. Brasília: DF. Disponível em: <http:// www.planalto.gov.br/ccivil_03/_ato2015-2018/2016/lei/ 113257.htm>. Acesso em: 10 de junho de 2018.

CIDH. Convenção Americana sobre Direitos Humanos. 1969. Disponível em:

$<$ http://www.cidh.org/Basicos/Portugues/c.Convencao_ Americana.htm>. Acesso em: 01/11/2017

EMERIQUE, Liliam Balmant (Org.) Direitos das minorias e grupos vulneráveis. Ijuí: Editora Unijuí, 2008.

FACHINETTO, Neidemar José. O direito à convivência familiar e comunitária: Contextualizado com as políticas públicas (in)existentes. Porto Alegre: Ed. Livraria do Advogado, 2009.

FREITAS, Marcos Cezar de (Org). História Social da Infância no Brasil. 3. ed. São Paulo: Cortez Editora, 2001.

HOUSSAIS, Antônio. Dicionário Houssais da Língua Portuguesa: elaborado no Instituto Antônio Houssais de
Lexicografia e Banco de Dados da Língua Portuguesa S/C Ltda. Rio de Janeiro: Editora Objetiva, 2001.

LIBERATI, Wilson Donizeti. Comentários ao Estatuto da Criança e do Adolescente. 11. ed. São Paulo: Malheiros Editores, 2010.

LÔBO, Paulo. Direito Civil: Famílias. 3. ed. São Paulo: Editora Saraiva, 2010.

OLIVEIRA, Gabriela Brandt. O direito à convivência familiar de crianças e adolescentes acolhidos: o MCA como instrumento efetivo para implementação deste direito. In: Censo da população infantojuvenil acolhida no Estado do Rio de Janeiro. MPRJ. Ano 2010, Rio de Janeiro. p. 393 -415 .

OLIVEIRA, Thalissa Corrêa. Evolução histórica dos direitos da criança e do adolescente com ênfase no ordenamento jurídico brasileiro. In: Revista da Faculdade de Direito de Valença. Ano 2013, Juiz de Fora. p. 339 - 356.

ONU. Declaração Universal dos Direitos Humanos. 1948. Disponível em: <http://www.onu.org.br/img/2014/09/ DUDH.pdf $>$. Acesso em: 01/11/2017

PAULA, Paulo Afonso Garrido de. Direito da Criança e do Adolescente e tutela jurisdicional diferenciada. São Paulo: Editora Revista dos Tribunais, 2002.

RAWLS, John. Uma teoria da justiça. Tradução: Juçara Simões. 4. ed. São Paulo: Martins Fontes, 2016.

SARAIVA, João Batista Costa. Adolescente em Conflito com a Lei: da indiferença a proteção integral. 4. ed. Porto Alegre: Editora Livraria do Advogado, 2013.

SARLET, Ingo Wolfgang. Dignidade da Pessoa Humana e Direitos Fundamentais na Constituição Federal de 1988. 5. ed. Porto Alegre: Livraria do Advogado, 2007.

SILVA, José Carlos Alves. Direitos e garantias fundamentais da criança e do adolescente institucionalizado: relação de cooperação com a sociedade civil. In: Revista o mal-estar no Direito: ROMED [recurso eletrônico]. Volume 2, n. 2. Ano 2016. p. 145 - 169. Disponível em: $<$ http:qqrevistaomalestarnodireito.com/volumei.html $>$. Acesso em: 05 de agosto de 2017.

SOUZA, Jadir Cirqueira de. A convivência familiar e comunitária e o acolhimento institucional. São Paulo: Editora Pillares, 2014.

UNICEF. Convenção sobre os Direitos da Criança. 1989. Disponível em: <https://www.unicef.org/brazil/pt/ resources_10120.htm>. Acesso em: 01/01/2017

Declaração Universal dos Direitos da Criança. Disponível em: <http://www.dhnet.org.br/direitos/sip/onu/ c_a/lex41.htm>. Acesso em: 01/11/2017

VERONESE, Josiane Rose Petry (Org). Direito da Criança e do Adolescente: novo curso - novos temas. Rio de Janeiro: Editora Lumen Juris, 2017. 